\title{
Porcine interferon lambda 3 (IFN- $\lambda 3$ ) shows potent anti-PRRSV activity in primary porcine alveolar macrophages (PAMs)
}

\author{
Jun Zhao ${ }^{1}$, Ling Zhu ${ }^{1,2}$, Lei Xu' ${ }^{1}$, Jianbo Huang ${ }^{1}$, Xiangang Sun ${ }^{1}$ and Zhiwen $X u^{1,2^{*}}$
}

\begin{abstract}
Background: Porcine reproductive and respiratory syndrome virus (PRRSV) is a serious viral disease of swine. At present, there are vaccines for the control of PRRSV infection, but the effect is not satisfactory. The recombination of attenuated vaccines causes significant difficulties with the prevention and control of PRRSV. Type III interferons (IFNs), also called IFN- $\lambda$ s, were newly identified and showed potent antiviral activity within the mucosal surface and immune organs.

Results: Therefore, primary porcine alveolar macrophages (PAMs) were used for this investigation. To this end, we found that the replication of PRRSV in PAMs was significantly reduced after pre-treatment with IFN- $\lambda$, and such inhibition was dose- and time-dependent. The plaque formation of PRRSV abrogated entirely, and virus yields were reduced by four orders of magnitude when the primary PAMs were treated with IFN- $\lambda 3$ at $1000 \mathrm{ng} / \mathrm{ml}$. In addition, IFN- $\lambda 3$ in our study was able to induce the expression of interferon-stimulated genes 15 (ISG15), 2'-5'-oligoadenylate synthase 1 (OAS1), IFN-inducible transmembrane 3 (IFITM3), and myxoma resistance protein 1(Mx1) in primary PAMs.
\end{abstract}

Conclusions: IFN- $\lambda 3$ had antiviral activity against PRRSV and can stimulate the expression of pivotal interferonstimulated genes (ISGs), i.e., ISG15, Mx1, OAS1, and IFITM3. So, IFN- $\lambda 3$ may serve as a useful antiviral agent.

Keywords: IFN- $\lambda$ 3, Primary PAMs, PRRSV, Antiviral activity

\section{Background}

Type I Interferons (IFN- $\alpha / \beta)$ and type III IFNs (IFN- $\lambda s$ ), as the first line of defence in innate immunity, play a crucial role in the body's resistance to exogenous pathogens [1]. Type III IFNs, also called IFN- $\lambda$ s, were first described in $2003[2,3]$, consist of IFN- $\lambda 1$, IFN- $\lambda 2$, IFN- $\lambda 3$ and IFN- $\lambda 4$ in humans $[4,5]$, IFN $-\lambda 2$ and IFN- $\lambda 3$ in mice $[6,7]$, IFN- $\lambda 1$ and IFN- $\lambda 3$ in swine $[8-10]$. Both IFN- $\alpha / \beta$ and IFN- $\lambda$ s bind to unique receptors and induce the previous signalling pathway and expression of

\footnotetext{
* Correspondence: abtcxzw@126.com

'College of Veterinary Medicine, Sichuan Agricultural University, Cheng Du, Sichuan Province, China

${ }^{2}$ Key Laboratory of Animal Disease and Human Health of Sichuan Province, Sichuan Agricultural University, Cheng Du, Sichuan Province, China
}

the IFN-stimulated genes (ISGs) to mediate antiviral activity. Type I IFN interacts with a receptor formed by Interferon alpha/beta receptor 1 (IFNAR1) and Interferon alpha/beta receptor 2 (IFNAR2). Type III IFNs bind to the specific receptor chain IFN- $\lambda$ R1 and IL-10R2 [11]. Type I IFN receptor is ubiquitously expressed in various types of cells and organs; However, IFN- $\lambda$ R 1 is widely expressed on epithelial cells, dendritic cells, human peripheral blood monocytes or macrophages [2], which means that IFN- $\lambda$ s may provide a focused antiviral response against mucosal and immune organ infections.

Interferon bind to its receptors on the cell surface and induce the production of a large number of ISGs, including ISG15, myxoma resistance protein (Mx) family, 2'- 
5 '-oligoadenylate synthase (OAS) family and the IFNinducible transmembrane (IFITM) family, through JAKSTAT signal transcription [12]. ISG15 is one of the most highly induced ISGs, ISG15 can inhibit viral translation, replication, or egress [13]. Mx1 is a broadly inhibitor and inhibits a wide range of viruses by blocking the endocytic traffic of incoming virus particles and the uncoating of ribonucleocapsids [14]. OAS1 can recognise the dsRNA produced by the virus in the infected cells and play an antiviral role by activating the ribonuclease L (RNase L) to degrade the diseased mRNA [15]. The IFN-inducible transmembrane (IFITM) family has a role in blocking virus entry [16]. IFITM3 has high potency against influenza A virus and severe acute respiratory syndrome (SARS) coronavirus [17].

PRRSV is a member of the family Arteriviridae in the order Nidovirales, which causes severe reproductive failure in sows and respiratory distress in piglets and growing pigs [18]. Also, PRRSV is an immunosuppressive virus that can infect the lymphatic system of the whole body and produce viraemia after infection [19]. PRRSV mainly infects and destroys porcine alveolar macrophages and leads to severe immunosuppression, which promotes the infection of Mycoplasma pneumoniae, Streptococcus, A. pleuropneumoniae, and other pathogens [20, 21]. The primary PAMs derived from piglet alveoli is an appropriate model for studying the interaction of PRRSV immune responses and host-pathogen in vitro. An in vivo antiviral test of type III interferons from pigs has not been reported. In this study, the antiviral activity of porcine IFN$\lambda 3$ against PRRSV in primary PAMs was evaluated, and the expressions of ISGs genes induced by IFN- $\lambda 3$ was also investigated in primary PAMs.

\section{Results}

IFN- $\lambda 3$ inhibits the replication of PRRSV in a dosedependent manner in primary PAM cells

Previous study has confirmed that porcine IFN- $\lambda 3$ possess the high specific activity against porcine epidemic diarrhoea virus (PEDV), classical swine fever virus (CSFV), hepatitis E virus (HEV) and so on [12, 22, 23]. In this study, we verified the antiviral effect of IFN- $\lambda 3$ against PRRSV in vitro on PAMs. As shown in Fig. 1, treatment of primary PAMs with IFN- $\lambda 3$ could reduce the multiplication of PRRSV. The degree of cytopathic effect (CPE) decreased with the increase in IFN- $\lambda 3$ concentration (Fig. 1 A-E). The number and size of viral plaques also decreased with the increase in IFN- $\lambda 3$ concentration (Fig. $1 \mathrm{~F}-\mathrm{J})$. The virus titre was significantly reduced with the increase of IFN- $\lambda 3$ treatment dose $(10$,
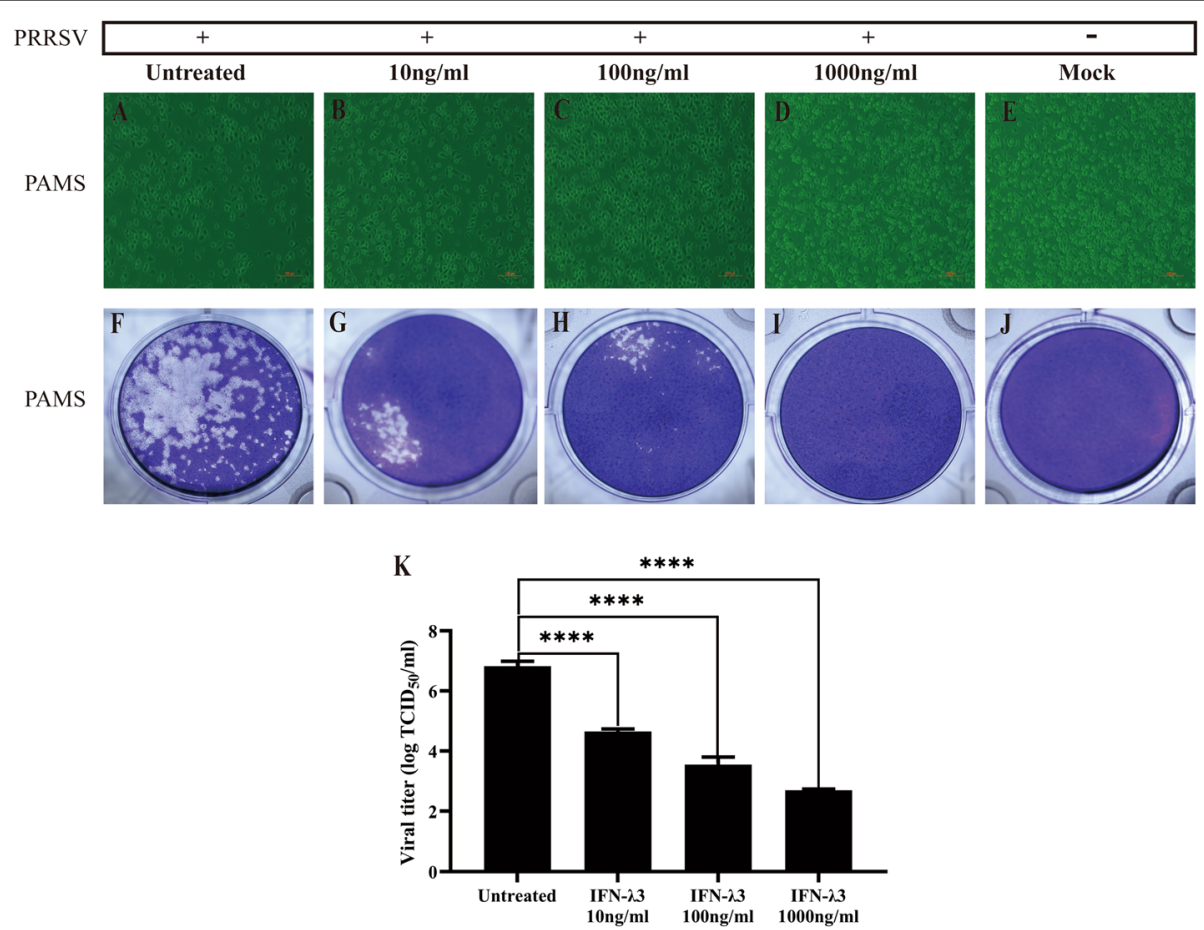

Fig. 1 The CPE of primary PAMs treated with Porcine IFN- $\lambda 3$ and infected with PRRSV. The primary PAMs were untreated or pre-treated with IFN$\lambda 3(10,100,1000 \mathrm{ng} / \mathrm{ml})$. b The primary PAMs not treated. $\mathbf{b}$ The primary PAMs treated with $10 \mathrm{ng} / \mathrm{ml}$ IFN- $\lambda$ 3. c The primary PAMs treated with $100 \mathrm{ng} / \mathrm{ml}$ IFN- $\lambda 3$. d The primary PAMs treated with $1000 \mathrm{ng} / \mathrm{ml}$ IFN- $\lambda 3$. e Control primary PAMs. $\mathbf{k}$ The primary PAMs were treated or untreated with $100 \mathrm{ng} / \mathrm{ml}$ of IFN- $\lambda 3$ for $12 \mathrm{~h}$ and then were infected with PRRSV NJ strain at $0.1 \mathrm{MOI}$. Infected cells were cultured for $12,24,36 \mathrm{or} 48 \mathrm{~h}$ after infection. $\mathbf{f}, \mathbf{g}, \mathbf{h}, \mathbf{i}, \mathbf{j}$ corresponds to $\mathbf{a}, \mathbf{b}, \mathbf{c}, \mathbf{d}$, e with the same treatment. Magnifications, $\times 200$ 
100, $1000 \mathrm{ng} / \mathrm{ml}$ ), and the maximum treatment dose could reduce the virus titre by four orders of magnitude compared with the control group (Fig. $1 \mathrm{~K}$, the raw data are shown in supplementary Table S1). These results indicate that the IFN- $\lambda 3$ could significantly inhibit the replication of PRRSV in a dose-dependent manner in primary PAMs.

\section{IFN- $\lambda 3$ inhibits the replication of PRRSV in a time-}

\section{dependent manner in primary PAM cells}

To investigate the time-dependent manner of the IFN$\lambda 3$ inhibits the replication of PRRSV, we used IFN- $\lambda 3$ of $100 \mathrm{ng} / \mathrm{ml}$ concentration to treat PAMs cells and infected with the PRRSV. Cell cultures were collected at specific time and determine the virus titre. As shown in Fig. 2 (The raw data are shown in supplementary file 1, Table S2), the inhibition of IFN- $\lambda 3$ on PRRSV decreased with time in primary PAMs, but the inhibition still existes. PRRSV proliferation slowed down within $36 \mathrm{~h}$ to $48 \mathrm{~h}$ in primary PAMs that were treated with IFN- $\lambda 3$. The above results showed that IFN $-\lambda 3$ could maintain a potent anti-PRRSV activity in the later stage and significantly inhibit the replication of PRRSV in a timedependent manner in primary PAMs.

\section{IFN- $\lambda 3$ inhibits PRRSV infection by activating ISGs in primary PAMs}

ISG15, Mx1, OAS1 and IFITM3 have well-known antiviral properties and may affect PRRSV replication. Therefore, we accessed the quantification of ISGs induce by IFN- $\lambda 3$. As seen in Fig. 3a to d, a dose-dependent induction of ISG15, Mx1, OAS1 and IFITM3 has been observed in primary PAMs treated with IFN- $\lambda 3$. The expression of mRNA for ISG15, Mx1, OAS1, and IFIT M3 was up-regulated by 70, 70, 160, and 15 times respectively at the concentration of $1000 \mathrm{ng} / \mathrm{ml}$ in primary PAMs. As shown in Fig. 3e and $\mathrm{f}$ (The full-length blots are presented in Supplementary file 2), a dosedependent induction of the antiviral proteins ISG15, Mx1 and OAS1 has been observed in primary PAMs treated with IFN- $\lambda 3$. The expression concentration of three antiviral proteins increased with the increasing IFN- $\lambda 3$ concentration. Both ISG15 and Mx1 showed low expression in the untreated condition, and IFN- $\lambda 3$ induced a large amount of expression. The expression of ISG15, Mx1 and OAS1 tended to be stable when the concentration of IFN- $\lambda 3$ was higher than $100 \mathrm{ng} / \mathrm{ml}$ (Fig. 3f).

\section{Discussion}

The results in our research confirm that the porcine IFN- $\lambda 3$ shows potent anti-PRRSV activity in primary PAMs. PAMs are the first line of defence against pathogenic microbe infections in the lung. PRRSV replicates in monocytic lineage cell types, particularly in PAMs, and causes immunosuppression in swine [24]. Therefore, we selected the primary PAMs to carry out the IFN- $\lambda 3$ in vitro anti-PRRSV study.

Alveolar macrophages are resident phagocytes of the alveolar space [24]. The expression of the IFN- $\lambda$ receptor in alveolar macrophages has been confirmed and reported [25]. Macrophages express IL-10R $\beta$ and IL-28R $\alpha$ at both the mRNA and protein levels [26]. IFN- $\lambda 3$ has the strongest antiviral function in IFN- $\lambda s$ [26]. In our study, the PRRSV proliferation reduced when primary PAMs were treated with IFN- $\lambda 3$ (1000 ng/ml) (Fig. 1i). IFN- $\lambda 3$ treatment could significantly reduce the virus titre of PRRSV proliferation on PAMs, and the virus titre of the $1000 \mathrm{ng} / \mathrm{ml}$ treatment group was four orders of magnitude lower than that of the control group (Fig. 2b). Consistent with these results, treatment with 10,100 or

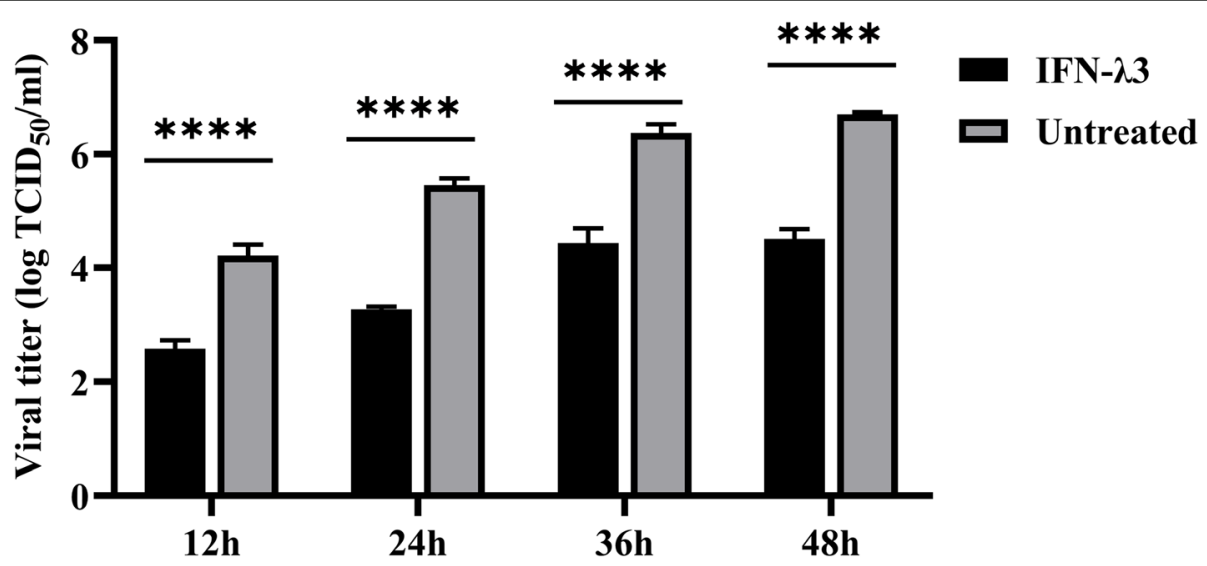

Fig. 2 IFN- $\lambda 3$ has antiviral activity against PRRSV and such inhibition is dose- and time-dependent in primary PAMs. The primary PAMs were stimulated with different doses of IFN- $\lambda 312 \mathrm{~h}$, and then infected with PRRSV at $0.1 \mathrm{MOI}$. Infected cells were cultured for $48 \mathrm{~h}$ after infection. Note that the virus titre was titrated by $\mathrm{TCID}_{50}$. Data were presented as mean $\pm \mathrm{SEM}(\mathrm{N}=3) .{ }^{*} P<0.05 ;{ }^{* *} P<0.01 ;{ }^{* * *} P<0.001 ;{ }^{* * *} P<0.0001$ by Unpaired T-test 

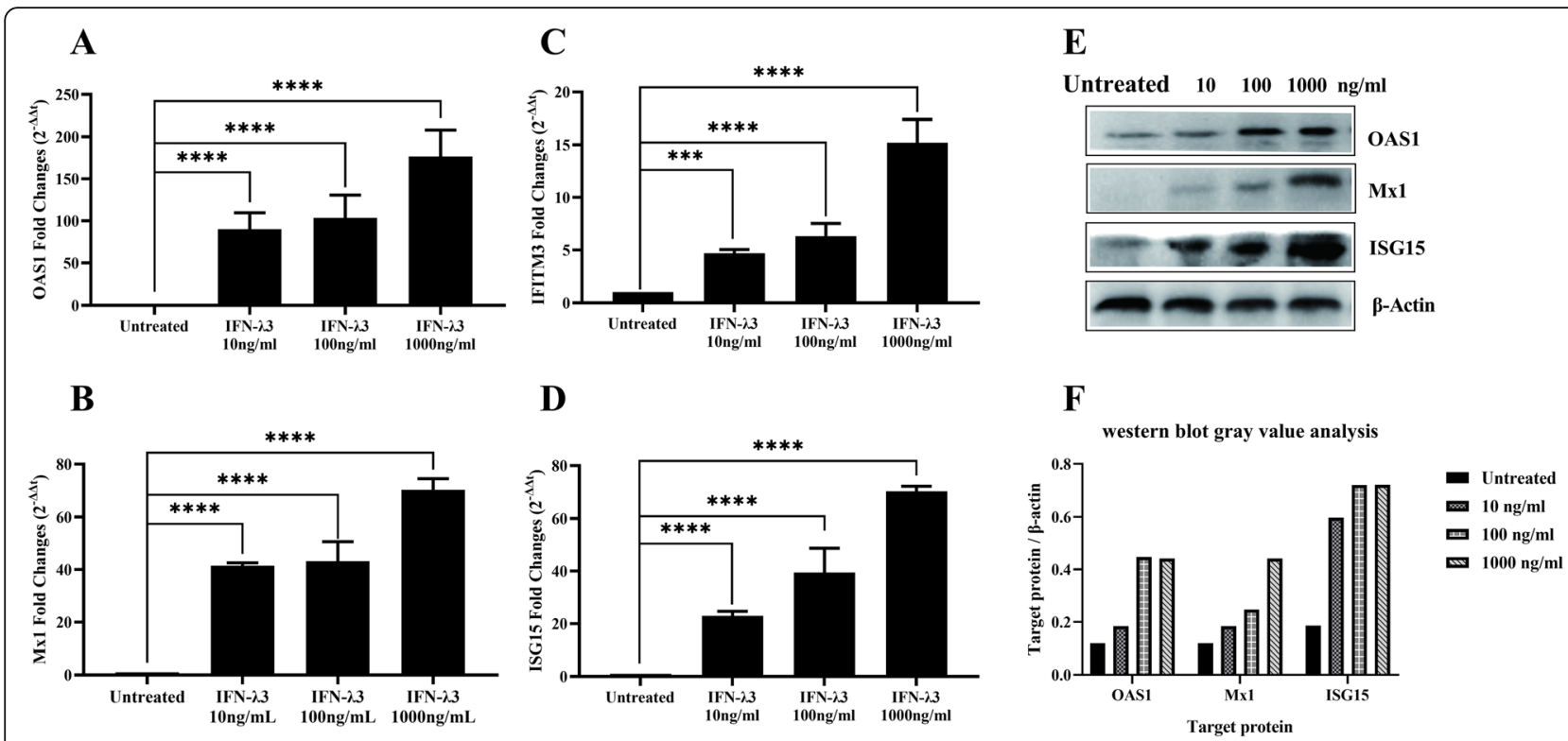

Fig. 3 Expressions of ISGs induced by IFN- $\lambda 3$ in primary PAMs. The primary PAMs were stimulated with different dose of IFN- $\lambda 3$ 12 h. qRT-PCR was performed to analyse the expression of $\operatorname{OAS1}(\mathbf{a}), \operatorname{Mx1}(\mathbf{b})$, IFITM3 (c), and ISG15 (d). The western blot was used to detect the proteins (e). The full-length blots are presented in Supplementary file 2 (a to d). The grey value of protein bands was measured by image J (f). Data were presented as mean \pm SEM $(N=3) .{ }^{*} P<0.05 ;{ }^{* *} P<0.01 ;{ }^{* *} P<0.001 ;{ }^{* * *} P<0.0001$ by Unpaired T-test

$1000 \mathrm{ng} / \mathrm{ml}$ doses of recombinant human IFN- $\lambda 3$ protected MARC-145 cells from PRRSV infection when compared to the untreated MARC-145 cells [27]. The study of two other kinds of viruses targeted porcine intestinal epithelial, PEDV and CSFV, confirming that IFN- $\lambda 3$ inhibits their infection in vitro $[22,28]$. All of these imply that porcine IFN- $\lambda 3$ can inhibit the proliferation of porcine viruses such as CSFV, PEDV and PRRSV.

The antiviral activities of IFN- $\lambda 3$ are due to ISG induction and IFN- $\lambda 3$ can induce the expression of ISG. IFN$\lambda 3$ exerts its anti-HIV function by activating JAK-STAT pathway-mediated innate immunity in macrophages [29]. IFN- $\lambda 3$ can bind to cell surface receptors and induce the high expression of interferon-stimulating genes of the MX, OAS and IFITM families [28, 30, 31]. The gene transcription profile induced by IFN- $\lambda 3$, particularly the gene transcription profile induced by IFN- $\lambda 3$ in primary PAMs has not been reported. In our study, we assessed whether the antiviral efficacy of IFN- $\lambda 3$ was caused by the levels of ISG expression induced by IFN- $\lambda 3$. Consistent with the expecting result, the expression of ISG15, OAS1, Mx1, and IFITM3 was provoked in primary PAM cells. The mRNA transcription and protein translation of the ISG15, OAS1 and Mx1 showed dose-dependence. However, the rangeability of mRNA and protein expression levels of ISG15, OAS1 and Mx1 were different. The expression levels of protein reached its peak when treated with $100 \mathrm{ng} / \mathrm{ml}$ IFN- $\lambda 3$ while the expression of mRNA continuous increased (Fig. 3).

\section{Conclusion}

In summary, our data demonstrated that IFN- $\lambda 3$ could inhibit the replication of PRRSV in Primary PAMs, and such inhibition is dose- and time-dependent. Alveolar macrophages are one of the earliest immune defence cells in the lungs that contact pathogenic microorganisms. They are essential components of the innate and specific immunity of the host [32]. PAMs are an essential host cell for PRRSV natural infection. IFN- $\lambda 3$ can stimulate the expression of pivotal ISGs, i.e. ISG15, Mx1, OAS1, and IFITM3. This study indicated that porcine IFN- $\lambda 3$ might serve as a promising therapeutic agent against PRRSV and other viruses in swine in the future.

\section{Methods}

\section{Virus and cells}

African green monkey embryonic kidney epithelial MARC145 cells were used to amplify PRRSV. MARC-145 cells were cultured with Dulbecco's Modified Eagle's medium (DMEM) (Gibco, USA) supplemented with antibiotics (100 units $/ \mathrm{ml}$ of penicillin and $100 \mathrm{mg} / \mathrm{ml}$ of streptomycin) $10 \%$ heat inactivated foetal bovine serum (FBS) (Gibco, USA) at $37{ }^{\circ} \mathrm{C}$ under $5 \% \mathrm{CO}_{2}$ atmosphere. PAMs were collected from lung lavages of 6-week-old Chenghua pigs (free of PRRSV, PCV2, PRV), as previously described, and cultured in RPMI-1640 (Gibco, USA) containing 10\% FBS (Gibco, USA) at $37^{\circ} \mathrm{C}$ [33]. PRRSV-NJ (NCBI GenBank accession No: MF818049.1) isolated from Sichuan province of China. The virus was propagated in MARC-145 cell with $2 \%$ FBS (Gibco, USA) added in the DMEM. 


\section{Antiviral assay}

To determine the anti-PRRSV activity of IFN- $\lambda 3$ in the primary PAMs, the E. coli-derived IFN- $\lambda 3$ was prepared in our laboratory. To explore the dose-dependent of IFN- $\lambda 3$ antiviral, primary PAMs were untreated or pretreated with IFN- $\lambda 3(10,100,1000 \mathrm{ng} / \mathrm{ml})$ for $12 \mathrm{~h}$. Then, the cells were infected with PRRSV NJ strain at 0.1 MOI for $1-2 \mathrm{~h}$, washed and replenished with fresh medium containing the indicated IFN- $\lambda 3$. Infected cells were cultured for $48 \mathrm{~h}$ after infection. To explore the time-dependent effect of IFN- $\lambda 3$ antiviral, primary PAMs were pre-treated with $100 \mathrm{ng} / \mathrm{ml}$ IFN- $\lambda 3$ for $12 \mathrm{~h}$. Then, the cells were infected with PRRSV NJ strain at 0.1 MOI for 1-2 h, washed and replenished with fresh medium containing the indicated IFN- $\lambda 3$. Infected cells were cultured for $12,24,36,48 \mathrm{~h}$ after infection. All of the cells were submitted to two freeze-thaw cycles and titrated by $50 \%$ tissue culture infective dose $\left(\right.$ TCID $\left._{50}\right)$ in Marc-145 cells. The cytopathic effect (CPE) units in culture plates were counted, and the viral titre analysis made use of the Reed-Muench Method. To examine the level of ISG expression in primary PAMs following IFN- $\lambda 3$ stimulation, the cells were stimulated with the indicated concentrations $(10,100,1000 \mathrm{ng} / \mathrm{ml})$ of IFN- $\lambda 3$ in 12 -well plates for $12 \mathrm{~h}$. Cells were then lysed, total RNA was extracted for subsequent qPCR analysis and total protein was extracted for western blot analysis. Every treatment group in this study had three duplicate samples $(N=3)$.

\section{Real-time quantitative PCR (qPCR)}

Total RNA was extracted from the cellular supernatant or cell lysates using the EZ-10 Spin Column Total RNA Isolation Kit (Sangon Biotech (Shanghai) Co., Ltd., China) according to the manufacturer's instructions and the RNA concentration was measured using a nucleic acid concentration analyzer (SCANDROP 200, Analytik Jena, Germany). Reverse transcription was performed using the Prime Script ${ }^{\mathrm{Tm}}$ II 1st Strand cDNA Synthesis Kit (TAKARA), and qPCR was performed in a Light Cycler 96 (Roche, Switzerland) with TB Green ${ }^{\bullet}$ Premix Ex Taq ${ }^{\mathrm{Tm}}$ II (Tli RNaseH Plus) (TAKARA). The thermal cycling conditions were $95^{\circ} \mathrm{C}$ for $30 \mathrm{~s}$, followed by 40 cycles of $95{ }^{\circ} \mathrm{C}$ for $5 \mathrm{~s}$, and $60{ }^{\circ} \mathrm{C}$ for $30 \mathrm{~s}$. All acquired data were obtained using Light Cycler 96 real-time PCR machines (Roche) and analysed with Light Cycler 96 software 1.5 based on the cycle threshold $(\Delta \Delta \mathrm{CT})$ method. Primers were designed using Oligo 6.0 software and are shown in Table 1.

\section{Western blot}

Total protein was extracted from the cell lysates using the Western and IP Cell lysis Buffer (Sangon Biotech (Shanghai) Co., Ltd., China) according to the manufacturer's instructions and protein concentration was
Table 1 Primers used in this study

\begin{tabular}{|c|c|c|c|}
\hline Genes & Primer names & Sequence $\left(5^{\prime}-3^{\prime}\right)$ & Product size (bp) \\
\hline \multirow[t]{2}{*}{$\overline{M x 1}$} & $M \times 1-F$ & CATCAACTTGGTGGTGGTC & 200 \\
\hline & $M \times 1-R$ & CAATCATGTAGCCCTTCTTC & \\
\hline \multirow[t]{2}{*}{$\beta$-actin } & $\beta$-actin- $F$ & ATCGTGCGGGACATCAAG & 179 \\
\hline & $\beta$-actin-R & GGAAGGAGGGCTGGAA & \\
\hline \multirow[t]{2}{*}{ ISG15 } & ISG15-F & TGAGGGACTGCATGATGGC & 197 \\
\hline & ISG15-R & CAGGATGCTCAGTGGGTCT & \\
\hline \multirow[t]{2}{*}{ IFITM3 } & IFITM3-F & GCTTCCCAGCCCTTCTTC & 142 \\
\hline & IFITM3-R & TCTCGCTTCGGATGTTGAT & \\
\hline \multirow[t]{2}{*}{ OAS1 } & OAS1-F & TCCGAACGCAGGTCAAGG & 136 \\
\hline & OAS1-R & AAGACGACGAGGTCAGCA & \\
\hline
\end{tabular}

determined using the BCA protein assay kit (Sangon Biotech (Shanghai) Co., Ltd., China). After gel electrophoresis, the proteins were transferred to nitrocellulose membranes (Bio-Rad, USA), and blocked in 5\% skim milk at $4{ }^{\circ} \mathrm{C}$ overnight. After washing with PBST $(0.5 \%$ Tween-20 in PBS), the membrane was incubated with primary antibodies for $2 \mathrm{~h}$ at $37^{\circ} \mathrm{C}$. After washing, the membrane was incubated with horseradish peroxidase (HRP)-conjugated IgG antibody (Abcam, No: ab170487) for $1 \mathrm{~h}$ at $37^{\circ} \mathrm{C}$. the protein bands were detected using SuperSignal $^{\mathrm{TM}}$ West Pico PLUS Chemiluminescent Substrate (Thermo Scientific, USA) and chemiluminescence imaging system (BIO-RAD, ChemiDoc MP, California, USA). The primary antibodies of ISG15 (No: ab233071), OAS1(NO: ab86343), Mx1(No: ab95926) and $\beta$-actin (No: ab179467) was purchased from Abcam.

\section{Statistical analysis}

Statistical analysis was performed and histogram were drawn using GraphPad Prism ${ }^{\text {Ts }}$ 8.0 (GraphPad Software, USA), Paired student $t$-test, and one-way ANOVA was used to test differences between different groups. $P$ values $<0.05$ were considered significant. The gray intensity of protein bolts was analyzed by Image J (National Institutes of Health, USA). The layouts and cropping of the pictures were completed by Adobe Illustrator CS6 (Adobe Systems Incorporated, California, USA).

\section{Supplementary Information}

The online version contains supplementary material available at https://doi. org/10.1186/s12917-020-02627-6.

Additional file 1: Table S1. The Viral titer at $48 \mathrm{~h}$ after the PAMs stimulated with different dose of IFN- $\lambda 3$. Table S2. The Viral titer at 12 , 24,36 or $48 \mathrm{~h}$ after the PAMs stimulated with IFN- $\lambda 3(100 \mathrm{ng} / \mathrm{ml})$.

Additional file 2: Supplementary Figure The antiviral proteins expression in PAMS treated with IFN- $\lambda 3$ detected by Western blot. The expression of the OAS1, Mx1, ISG15 and $\beta$-actin proteins were detected by Western blot. d) Original blot images of OAS1, Mx1, ISG15 and $\beta$-actin in the Fig. 3e after treatment with IFN- $\lambda 3(10,100,1000 \mathrm{ng} / \mathrm{ml})$. 


\section{Abbreviations}

IFN- $\lambda$ 3: Interferon lambda 3; PAMs: Porcine alveolar macrophages: PRRSV: Porcine reproductive and respiratory syndrome virus; IFNs: Interferons; ISG15: Interferon-stimulated genes 15; OAS1: 2'-5'-Oligoadenylate synthase 1; IFITM3: IFN-inducible transmembrane 3; Mx1: Myxoma resistance protein 1; ISGs: Interferon-stimulated genes; IFN-a: Interferon alpha; IFN- $\beta$ : Interferon beta; IFN- $\lambda$ s: Interferon lambdas; IFN- $\lambda$ 1: Interferon lambda 1 ; IFN$\lambda 2$ : Interferon lambda 2; IFN- $\lambda 4$ : Interferon lambda 4; IFNAR1: Interferon alpha/beta receptor 1; IFNAR2: Interferon alpha/beta receptor 2; IFN$\lambda R 1$ : Interferon lambda receptor 1; IL-10R2: Interleukin 10 receptor 2; mRNA: Messenger RNA; SARS: Severe acute respiratory syndrome; PEDV: Porcine epidemic diarrhoea virus; CSFV: Classical swine fever virus; HEV: Hepatitis E virus; CPE: Cytopathic effect; IL-10Rß: Interleukin 10 receptor beta; IL-28Ra: Interleukin 28 receptor alpha; HIV: Human immunodeficiency virus: MARC-145: African green monkey embryonic kidney epithelial cells: DMEM: Dulbecco's modified eagle's medium; FBS: Foetal bovine serum; PCV2: Porcine circovirus type 2; PRV: Pseudorabies virus; MOI: Multiplicity of infection; TCID50: 50\% tissue culture infective dose; qPCR: Real-time polymerase chain reaction; PBST: 0.5\% Tween-20 in PBS; HRP: Horseradish peroxidase; IgG: Immunoglobulin G

\section{Acknowledgments}

We thank Prof. Zhu for her insightful comments on the design of the study.

\section{Authors' contributions}

$J Z, Z X$ and LZ conceived and designed the experiments. JZ performed the experiments. JZ and JH performed the analysis. JZ and LX drafted the manuscript. XS substantively revised this manuscript. All authors read and approved the final manuscript.

\section{Funding}

This work was supported by Program Sichuan Veterinary Medicine and Drug Innovation Group of China Agricultural Research System (CARS-SVDIP), National Key Research Program during the 13st Five-year Plan Period of China: Research and Demonstration of Purification Technology of Pseudorabies (2018YFD0500802). The funders had no role in the design of the collection, analysis, and interpretation of data.

\section{Availability of data and materials}

All data generated during this study are included in supplementary file 1 (Table S1, S2). However, the raw data is available from the corresponding author upon reasonable request.

\section{Ethics approval and consent to participate}

The Sichuan provincial laboratory animal management committee (Licence No: SYXK (chuan) 2019-187) approval has been received. The "Guidelines for Experimental Animals" of the Ministry of Science and Technology (Beijing, China) were followed.

\section{Consent for publication}

Not applicable.

\section{Competing interests}

The authors declare that they have no competing interest.

Received: 12 November 2019 Accepted: 19 October 2020

Published online: 28 October 2020

\section{References}

1. Sadler AJ, Williams BRG. Interferon-inducible antiviral effectors. Nat Rev Immunol. 2008:8:559-68.

2. Sheppard P, Kindsvogel W, Xu W, Henderson K, Schlutsmeyer S, Whitmore TE, et al. IL-28, IL-29 and their class II cytokine receptor IL-28R. Nat Immunol. 2003;4:63-8

3. Kotenko SV, Gallagher GBaurin W, Lewis AA, Shen M, Shah NK, Langer JA, et al. IFN-lambdas mediate antiviral protection through a distinct class II cytokine receptor complex. Nat Immunol. 2003;4:69-77.

4. O'Brien TR, Ludmila PO, Donnelly RP. IFN- $\lambda$ 4: the paradoxical new member of the interferon lambda family. J Interf Cytokine Res. 2014;34:829-38.

5. Donnelly RP, Kotenko SV. Interferon-lambda: a new addition to an old family. J Interf Cytokine Res. 2010;30:555-64.
6. Bartlett NW, Buttigieg K, Kotenko SV, Smith GL. Murine interferon lambdas (type III interferons) exhibit potent antiviral activity in vivo in a poxvirus infection model. J Gen Virol. 2005;86:1589.

7. Ahmed L, Anita LA, Smirnov SV, Shubha A, Walid A, Bin T, et al. Characterisation of the mouse IFN-lambda ligand-receptor system: IFNlambdas exhibit antitumor activity against B16 melanoma. Cancer Res. 2006; 66:4468-77.

8. Wang D, Fang L, Zhao F, Luo R, Chen H, Xiao S. Molecular cloning, expression and antiviral activity of porcine interleukin-29 (poll-29). Dev Comp Immunol. 2011;35:378-84.

9. Shen $\mathrm{H}$, Short communication. Antiviral activity of porcine IFN- $\lambda 3$ against porcine epidemic diarrhea virus in vitro. Virus Genes. 2016;52(6):1-6.

10. Yongming S, Rowland RRR, Frank B. Molecular characterisation and antiviral analyses of porcine type III interferons. J Interf Cytokine Res. 2010;30:801.

11. Kotenko SV, Durbin JE. Contribution of type III interferons to antiviral immunity: location, location, location. J Biol Chem. 2017;292:7295.

12. Schneider WM, Chevillotte MD, Rice CM. Interferon-stimulated genes: a complex web of host defences. Annu Rev Immunol. 2014;32:513-45.

13. Zhao C, Collins MN, Hsiang TY, Krug RM. Interferon-induced ISG15 pathway: an ongoing virus-host battle. Trends Microbiol. 2013;21:181-6.

14. Gao S, Malsburg AVD, Paeschke S, Behlke J, Haller O, Kochs G, Daumke O. Structural basis of oligomerisation in the stalk region of dynamin-like MxA. Nature. 2010:465:502-6.

15. Silverman RH. Viral encounters with 2',5'-oligoadenylate synthetase and RNase $L$ during the interferon antiviral response. J Virol. 2007:81:12720.

16. Schoggins JW, Wilson SJ, Panis M, Murphy MY, Jones $C T$, Bieniasz P, Rice CM. A diverse range of gene products are effectors of the type I interferon antiviral response. Nature. 2011;472:481-5.

17. Huang I, Bailey CC, Weyer JL, Radoshitzky SR, Becker MM. Distinct patterns of IFITM-mediated restriction of filoviruses, SARS coronavirus, and influenza a virus. PLoS Pathog. 2011;7:e1001258.

18. Rossow KD. Porcine reproductive and respiratory syndrome. Ciência Rural. 1998;28:656-64.

19. Li Y, Wang X, Bo K, Wang X, Bo T, Yang B, et al. Emergence of a highly pathogenic porcine reproductive and respiratory syndrome virus in the mid-eastern region of China. Vet J. 2007:174:577-84.

20. Chiou MT, Jeng CR, Chueh LL, Cheng CH, Pang VF. Effects of porcine reproductive and respiratory syndrome virus (isolate tw91) on porcine alveolar macrophages in vitro. Vet Microbiol. 2000;71:9-25.

21. Tracy H, Bell TJ. Alveolar macrophages: plasticity in a tissue-specific context. Nat Rev Immunol. 2014;14:81-93.

22. Kegong T, Xiuling Y, Tiezhu Z, Youjun F, Zhen C, Chuanbin W, et al. Emergence of fatal PRRSV variants: unparalleled outbreaks of atypical PRRS in China and molecular dissection of the unique hallmark. PLoS One. 2007:2:e526.

23. Liang L, Mei X, Fang F, Lingdan Y, Pinghuang L. IFN-lambda 3 mediates antiviral protection against porcine epidemic diarrhoea virus by inducing a distinct antiviral transcript profile in porcine intestinal epithelia. Front Immunol. 2019;10:2394.

24. Kavanová L, Prodělalová J, Nedbalcová K, Matiašovic J, Volf J, Faldyna M, Salát J. Immune response of porcine alveolar macrophages to a concurrent infection with porcine reproductive and respiratory syndrome virus and Haemophilus parasuis in vitro. Vet Microbiol. 2015;180(1-2):28-35.

25. Hou W, Wang X, Ye L, Zhou L, Yang Z, Riedel E, Ho W. Lambda interferon inhibits human immunodeficiency virus type 1 infection of macrophages. J Virol. 83:3834-42.

26. Wang Y, Li J, Wang X, Zhou Y, Zhang T, Ho W. Comparison of antiviral activity of lambda-interferons against HIV replication in macrophages. J Interf Cytokine Res. 2015;35(3):213-21.

27. Robek MD, Boyd BS, Chisari FV. Lambda interferon inhibits hepatitis B and C virus replication. J Virol. 2005;79(6):3851-4.

28. Shen $\mathrm{H}$. Short communication: antiviral activity of porcine IFN-k3 against porcine epidemic diarrhoea virus in vitro. Virus Genes. 2016;52:1-6.

29. Liu MQ, Zhou DJ, Wang X, Zhou W, Ye L, Li JL, Wang YZ, Ho WZ. IFN- $\lambda 3$ inhibits HIV infection of macrophages through the JAK-STAT pathway. PLoS One. 2012;7:e35902.

30. Luo R, Fang L, Jin H, Jiang Y, Wang $D$, Chen $H$, Xiao S. Antiviral activity of type I and type III interferons against porcine reproductive and respiratory syndrome virus (PRRSV). Antivir Res. 2011:91:99-101.

31. Li L, Fu F, Xue M, Chen W, Liu J, Shi H, Chen J, Bu Z, Feng L, Liu P. IFNlambda preferably inhibits PEDV infection of porcine intestinal epithelial cells compared with IFN-alpha. Antivir Res. 2017;140:76-82. 
32. Hussell T, Bell TJ. Alveolar macrophages: plasticity in a tissue-specific context. Nat Rev Immunol. 2014;14:81-93.

33. Zelnickova P, Matiasovic J, Pavlova B, Kudlackova H, Faldyna M. Quantitative nitric oxide production by rat, bovine and porcine macrophages. Nitric Oxide-Biol Ch. 2008;19:36-41.

\section{Publisher's Note}

Springer Nature remains neutral with regard to jurisdictional claims in published maps and institutional affiliations.

Ready to submit your research? Choose BMC and benefit from:

- fast, convenient online submission

- thorough peer review by experienced researchers in your field

- rapid publication on acceptance

- support for research data, including large and complex data types

- gold Open Access which fosters wider collaboration and increased citations

- maximum visibility for your research: over $100 \mathrm{M}$ website views per year

At $\mathrm{BMC}$, research is always in progress.

Learn more biomedcentral.com/submissions 